\title{
Study on Genetic Diversity in Indian Mustard (Brassica juncea L. Czern. \& Coss.)
}

\author{
Ankit Mishra ${ }^{1 *}$, R.K. Singh ${ }^{2}$, Naresh Kumar $L^{3}$. and Praveen Kumar $\mathbf{U}^{4}$

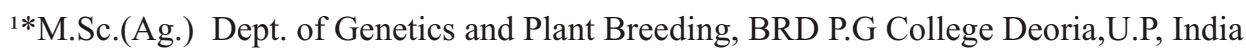 \\ ${ }^{2}$ Assistant Prof. Dept. of GPB, BRD P.G College Deoria,U.P, India \\ ${ }^{3} \mathrm{Ph}$. D Scholar Dept. of GPB, SHIATS, Allahabad, India \\ ${ }^{4}$ M.Sc.(Ag.) Dept. of GPB, SHIATS, Allahabad, India
}

Received: 20 October 2020/Accepted: 25 November 2020

URL:https://doi.org/10.38112/agw.2020.v08i02.008

\begin{abstract}
Genetic diversity in crop species plays an important role for breeding new cultivars than existing ones in available germplasm. Therefore, 50 Indian mustard genotypes evaluated for the extent of diversity for utilization in breeding program. The data recorded on thirteen characters were subjected to analysis of variance and dispersion revealed significant differences. D2 analysis was conducted to measure the genetic diversity among the genotypes. The genotypes were grouped in 9 clusters using Tocher's method. Intra-cluster distance was maximum for cluster V followed by cluster IV. The highest inter cluster distance was observed between the cluster VII and IX followed by VII and VIII and the lowest between cluster I and III. The characteristics such as oil content, test weight and number of siliquae per plant contributed greatest towards the divergence in the mustard genotypes. The genotypes RC 502 and RC 510 of cluster VII constitute high cluster mean for number of siliquae per plant, number of secondary branches per plant along with earliness in flowering; the genotype RC 524 of cluster IX for high oil yield along with early maturity and genotype RC 535 of cluster VIII for high seed yield per plant and test weight. These genotypes could be considered as best parents and can be utilized in the hybridization programme in different combinations for selection of transgressive segregants and high heterotic response to get maximum yield alongwith early maturity and high oil content.
\end{abstract}

Keywords: Brassica juncea L., Indian mustard, Genetic divergence, D2 analysis ,Cluster analysis

\section{Introduction}

Indian mustard [Brassica juncea (L.) Czern. \& Coss ] popularly known as rai is one of the most important oilseed crops of the country occupying considerably larger acreage among the Brassica crops. Rape seed mustard crop account for almost 14 percent of the edible vegetable oil supply of the world demand (Kour and Singh 2004).

The crops are cultivated on an area of 6.70 million ha with a net production of 7.96 million tonnes, and an average yield of $1188 \mathrm{~kg} / \mathrm{ha}$ (Agriculture Statistics at a glance 2014) . It is cultivated in rabi season mainly in Northwest India, and contributes nearly 27 per cent to edible oil pool of the country (Singh et al., 2010). The main objective in Brassica (rapeseed and mustard) breeding is to improve the seed and oil quality to meet the potential edible and industrial oil requirements (Shengwu et al., 2003).

In crop improvement, genetic diversity is the pre-requisite to develop hybrids between genotypes of diverse origin displaying greater heterosis, broad spectrum of variability and obtaining desirable recombinants in segregating generations than those between closely related parents. The breeder requires comprehensive knowledge on diversity in available germplasm to breed new cultivars with increased yield, wider adaptability and desirable quality than existing ones.

Keeping these points in mind, the present study was undertaken to estimate the magnitude of genetic diversity in the available genotypes and identify divergent parents for hybridization program, which would provide superior segregates in mustard genotypes.

\section{Material and Methods}

The present investigation was conducted during rabi 2013-14 to evaluate 50 genotypes of Indian mustard Brassica juncea (L.). The experiment was conducted at the 
Field Experimentation Centre, Department of Genetics and Plant Breeding, B.R.D.P.G. College, at Deoria in Randomized Block Design (RBD) with three replications. Deoria is located in the East part of Uttar Pradesh, India. The site of experiment is located at $26.5^{\circ} \mathrm{N}$ latitude, $83.79^{\circ}$ E longitude and 68 meter (223 feet) above the sea level.Row to row and plant to plant distance was kept at 30 and $15 \mathrm{~cm}$, respectively. The recommended doses of fertilizers@ 80:40:40 N: P2 O5: K2O kg per hectare were applied and agricultural package of practices was followed to raise a healthy crop. The data were recorded on thirteen characters viz. Days to $50 \%$ flowering, Plant height $(\mathrm{cm})$, Main raceme length $(\mathrm{cm})$, Number of Primary branches per plant, Number of Secondary branches per plant, Number of Siliquae on main raceme, Number of siliquae per plant, Days to maturity, Biological yield per plant (g), Harvest index, Test weight $(\mathrm{g})$ and Seed yield per plant $(\mathrm{g})$ and Oil content (\%). $\mathrm{D}^{2}$ statistics analysis by Mahalanobis (1936) was used for assessing genetic divergence among all the genotypes. The clustering of $\mathrm{D}^{2}$ values was done using Tocher's method as described by Rao (1952).

\section{Result and Discussion}

The analysis of variance and dispersion were highly significant among all the genotypes for all thirteen characters studied which revealed the presence of considerable genetic variability among the genotypes. The fifty genotypes were grouped into 9 clusters using the Tocher's method (Table 1). Out of 9 clusters, cluster V was the largest comprising 12 genotypes followed by cluster I with 10 genotypes and cluster IV with 8 genotypes; clusters VI, II, III, VII, VIII and IX contained $6,6,4,2,1$ and 1 genotypes respectively. The clustering pattern showed considerable diversity among different genotypes. It exhibited that there was no relationship between genetic and geographical diversity as genotypes of same geographical region were grouped into different clusters and vice versa as supported by earlier findings by Binod et al.(2013) and Jeena and Sheik(2003). This could be due to genetic drift, selection pressure and environmental effect, which create morphological diversity rather than actual genetic distances as suggested by Balvir et al (2013).

The characters viz. Oil content(53.47) followed by test weight (26.37), number of siliquae per plant(15.27) contributed more than $95 \%$ towards the total divergence (Table 2). Parallel to the present results, maximum contribution towards the divergence for Oil content was previously reported by Sutariya et al.(2011); for test weight by Ratnesh Pandey et al.(2013) and for number of siliquae per plant by Shalini et al. (2000) and Neelam et al.(2014).

The cluster means for different characters are presented in (Table 3). Cluster VII possessed high mean values for number of siliqua per plant (493.200) followed by plant height (171.367), biological yield per plant (66.00) and number of secondary branches per plant (21.20) ; cluster VIII for days to maturity (132.333) followed by seed yield per plant (13.800) and days to 50\% flowering (62.667); cluster III for main raceme length (90.917) followed by Siliquaes on main raceme (62.883) and harvest index (31.168); cluster V for primary branches per plant(5.056) and test weight (4.972); cluster IX for Oil content (41.117). However, genotypes of clusters VIII had maximum for seed yield per plant(13.800) having dwarf plant height (149.600) with desirable rating for seed index (29.923) and oil content(40.507); cluster VII was more for number of siliquae per plant(493.200) followed by plant height (171.367), number of secondary branches per plant(21.200) with desirable rating for seed yield per plant(13.733) and test weight (4.967) ; cluster IX had minimum value for days to maturity (129.00) and more in oil content (41.117). This reflected probability of getting better segregants and primary recombinants if good parents be selected for hybridization on mean basis, which was in accordance as earlier reported by Binod et al.(2013) had high cluster mean for primary branches per plant, secondary branches per plant, number of siliqua per plant, number of seeds per siliqua, biological yield per plant and seed yield per plant, Singh et al.(2014) showed high cluster mean for seed yield per plant and number of pods per plant.

The magnitude of inter- cluster distances was greater than intra-cluster distances suggesting the presence of considerable diversity among the clusters (Table 4). The cluster V exhibited maximum intra-cluster distance ( 371.024) followed by cluster IV (291.238) which indicates that genotypes in this cluster are more diverse than the other clusters. Maximum intercluster distance was observed between cluster VII and IX ( 5166.976) followed by clusterVII and VIII (4066.648); cluster IV and VII (2385.986); cluster VI and IX (2379.225); cluster V and IX (1960.894); cluster III and IX (1930.018); cluster VI and VIII (1533.895), and cluster V and VIII (1503.255 ). The larger intercluster distance genotypes grouped in these clusters are different from genotype of other cluster for one or more characters and are more divergent. Hence, these can be selected and utilized in hybridization programme to produce more trangressive segregants and greater heterosis in F1 when crossed. 
Table 1: Clustering pattern of 50 genotypes of Indian mustard

\begin{tabular}{c|c|l}
\hline Cluster & No. of genotypes & \multicolumn{1}{c}{ Genotypes } \\
\hline I & 10 & RC 533, RC 536, RC 537, RC 531, RC 512, RC 513, RC 539, RC 520, RC 523, RC 528 \\
\hline II & 6 & RC 534, RC 538, RC 530, RC 540, Kranti, RC 507 \\
\hline III & 4 & RC 519, RC 526, RC 525, RC 527 \\
\hline IV & 8 & RC 514, RC 515, RC 511, RLM 198, RC 532, RC 518, RC 509,JD-6 \\
\hline V & 12 & RC 505, RC 508, RC 503, RC 504, RC 517, Rohini, RC 501,RH 30, RC 521, Pusabahar,NDRE-4, Vardan \\
\hline VI & 6 & Jawahar-1,RC 522, RC 506, RC 529, RC 516, Pusabold \\
\hline VII & 2 & RC 502, RC 510 \\
\hline VIII & 1 & RC 535 \\
\hline IX & 1 & RC 524
\end{tabular}

Table 2: Per cent contribution of each character towards divergence in Indian mustard

\begin{tabular}{c|l|c|c}
\hline S. No. & Source & Times Ranked 1st & Contribution \% \\
\hline 1. & Days to 50\% Flowering & 0.01 & 0.00 \\
\hline 2. & Plant Height (cm) & 2 & 0.16 \\
\hline 3. & Main Raceme Length $(\mathrm{cm})$ & 7 & 0.57 \\
\hline 4. & Primary Branches/ Plant & 0.01 & 0.00 \\
\hline 5. & Secondary Branches/ Plant & 2 & 0.16 \\
\hline 6. & Siliquaes On Main Raceme & 26 & 2.12 \\
\hline 7. & Siliqua/ Plant & 187 & 15.27 \\
\hline 8. & Days to Maturity & 0.01 & 0.00 \\
\hline 9. & Biological Yield/ Plant $(\mathrm{g})$ & 23 & 1.88 \\
\hline 10. & Seed Yield/ Plant $(\mathrm{g})$ & 0.01 & 0.00 \\
\hline 11. & Harvest Index & 0.01 & 0.00 \\
\hline 12. & Test Weight $(\mathrm{g})$ & 323 & 26.37 \\
\hline 13. & Oil Content $\%$ & 655 & 53.47 \\
\hline
\end{tabular}

Table 3: Cluster means for 13 characters of 25 mustard genotypes.

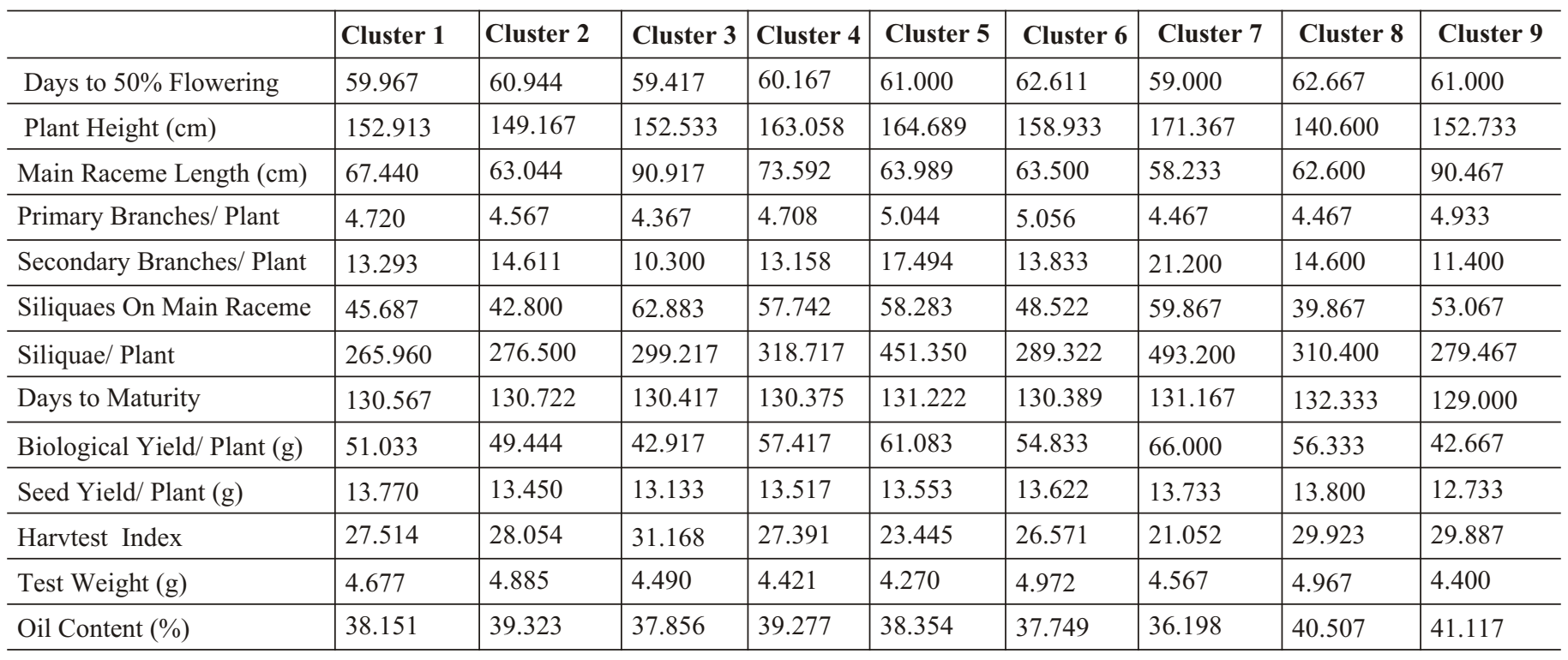


Ankit Mishra et. al.

Table 4: Average intra and inter cluster D2 values among the cluster for 46 Indian mustard genotypes.

\begin{tabular}{|c|c|c|c|c|c|c|c|c|c|}
\hline & 1 Cluster & 2 Cluster & 3 Cluster & 4 Cluster & 5 Cluster & 6 Cluster & 7 Cluster & 8 Cluster & 9 Cluster \\
\hline 1 Cluster & 90.618 & 307.380 & 211.104 & 454.727 & 581.115 & 285.069 & 1410.717 & 978.563 & 1611.705 \\
\hline 2 Cluster & & 93.434 & 607.658 & 311.938 & 859.268 & 669.040 & 2517.731 & 291.489 & 757.055 \\
\hline 3 Cluster & & & 120.310 & 589.211 & 520.062 & 387.571 & 1116.534 & 1437.105 & 1930.018 \\
\hline 4 Cluster & & & & 291.238 & 672.397 & 892.366 & 2385.986 & 549.567 & 773.448 \\
\hline 5 Cluster & & & & & 371.024 & 832.552 & 1141.366 & 1503.255 & 1960.894 \\
\hline 6 Cluster & & & & & & 274.053 & 1212.563 & 1533.895 & 2379.225 \\
\hline 7 Cluster & & & & & & & 125.496 & 4066.648 & 5166.976 \\
\hline 8 Cluster & & & & & & & & 0.000 & 263.364 \\
\hline 9 Cluster & & & & & & & & & 0.000 \\
\hline
\end{tabular}

\section{References}

Agriculture Statistics at a glance (2014) Directorate of Economics and Statistics, Department of Agriculture and Cooperation ,Government of India ministry of Agriculture 4.1.16: 172.

Binod Kumar, Anil Pandey And Sanjay Kr. (2013). Genetic Diversity For Agro-Morphological And Oil quality Traits In Indian Mustard (Brassica Juncea L.Czern \& Coss) Bioscan 8(3): 771-775.

Neelam Shekhawat Jadeja, G. C. Jogendra Singh Ramesh (2014).Genetic diversity analysis in relation to seed yield and its component traits in Indian mustard (Brassica juncea L. Czern \& Coss). Bioscan. 9(2):713-717. 26 .

Singh. D, Arya, RK, Chandra, N, Niwas, R and Salisbury, P. (2010) Genetic diversity studies in relation to seed yield and its component traits in Indian mustard [Brassica juncea (L.) Czern \& Coss.]. J. Oilseeds Brassica, 1: 19-22.

Shalini, T. S. Sheriff, R. A. Kulkarni, R. S. Venkataravana, P. (2000). Genetic divergence in Indian mustard (Brassica juncea L. Czern and Coss). Journal of Agricultural Sciences; 34(3):251-256. 8

Sutariya, D. A. Patel, K. M. Bhadauria, H. S. Vaghela, P. O. Prajapati, D. V. Parmar, S. K.(2011) Genetic diversity for quality traits in Indian mustard [Brassica juncea (L.)]. Journal of Oilseed Brassica; 2(1):44-47. 7.
Jeena, A. S. and Sheikh, F. A. (2003). Genetic divergence analysis ingobhi sarson (Brassica napus L.) J. Oilseed Res. 20: 210-212.

Kour, A. and S. P. Singh. 2004. Evaluation of genetic diversity in different genotypes of Brassica juncea by SDS-PAGE. Crop Science - ICSC2004.

Mahalanobis, P.C., (1936). On the generalized distance in statistics. Proc. Natl. Acad. Sa., Indian, 12: 49-55.

Ratnesh Pandey Brajesh Kumar Manoj Kumar (2013). Genetic divergence for quantitative traits in Indian mustard (Brassica juncea L. Czern \& Coss). American-Eurasian Journal of Agricultural \& Environmental Sciences; 13(3):348-351. 11

Rao, C.R., (1952), Advanced Statistical Methods in Biometrieal Research. John Wiley and Sons, Inc.,New York, pp. 357-363.

Shengwu, H.U., J. Ovensa, L. Kucera, V. Kucera and M. Vyvadilova., 2003. Evaluation of genetic diversity of Brassica napus germplasm from China and Europe. Plant Soil Environ., 49: 106-113.

Singh, N. P. Sharma, P. K. Vivek Kumar Vijay Kumar Malik, V. K. (2014). Genetic divergence analysis in Indian mustard [Brassica juncea (L.) Czern \& Coss.]. AbstractsAnnals of Biology; 30(2):296-298. 14.

Binod Kumar Anil Pandey(2013). Diversity analysis in Indian mustard (Brassica juncea L. Czern \& Coss). Madras Agricultural Journal; 2013. 100(1/3):62-66. 17. 